At Turots: Jurnal Pendidikan Islam
Vol. 3, No.1, Juni 2021, pp. 21-30
Print ISSN : 2656-7555 || Online ISSN : 2747-089X
http://journal.stitmadani.ac.id/index.php/JPI/index

\title{
Pembelajaran Tahfidzul Qur'an Kelas III Putra di Madrasah Salafiyah Ula Islamic Centre Bin Baz Yogyakarta
}

\author{
Eko Ngabdul Shodikin a,1, ${ }^{*}$, Faiz Naufal b,2, Rendiansyah ${ }^{\text {b,3 }}$ \\ a Ponpes Jamilurrohman, Yogyakarta, Indonesia; \\ b Sekolah Tinggi Ilmu Tarbiyah Madani Yogyakarta; \\ *1 pejuangc92@gmail.com; ${ }^{2}$ faiz.syafaat98@gmail.com; ${ }^{3}$ rendiansyah.studentyle@gmail.com
}

\section{KAT A KUNCI}

Pembelajaran Tahfidzul Qur'an Salafiyah Ula Islamic Centre Bin Baz

Kurikulum Tahfidz

\section{KEYWORDS}

Learning Tahfidzul Qur'an Salafiyah Ula Islamic Centre Bin Baz

Tahfidz Curriculum

\section{ABSTRAK}

Pada tingkat Salafiyah Ula (SU) muatan kurikulum tahfidznya paling banyak dibandingkan pada jenjang lainnya. Pengurus Islamic Centre Bin Baz (ICBB) menyadari bahwa anak-anak pada usia SD masih memiliki potensi otak yang luar biasa. Otak dan hati mereka masih jernih belum banyak terkontaminasi oleh pengaruh-pengaruh negatif, sehingga pada usia ini sangat bagus digunakan untuk banyak menghafal Al-Qur'an. Siswa lulusan jenjang Salafiyah Ula ini ditargetkan mempunyai hafalan 6 juz atau rata-rata mereka ditargetkan hafal 1 juz per tahun. Untuk mencapai target hafalan sebanyak itu, maka pihak lembaga memberikan porsi jam tahfidz yang cukup besar yaitu 3 jam per hari dari jam 07.00 - 10.30. Penelitian bertujuan untuk mengetahui pelaksaanaan pembelajaran tahfidzul Qur'an, hasil pelaksanaan pembelajaran tahfidzul Qur'an dan untuk mengetahui faktor penghambat dan pendukung pelaksanaan pembelajaran tahfidzul Qur'an kelas III di Madrasah Salafiyah Ula Islamic Centre Bin Baz Yogyakarta.

\section{Class III Men's Tahfidzul Qur'an Learning at Madrasah Salafiyah Ula Islamic Center Bin Baz Yogyakarta}

At the Salafiyah Ula (SU) level, the content of the tahfidz curriculum is the most compared to other levels. The management of the Islamic Center Bin Baz (ICBB) realizes that children at elementary school age still have extraordinary brain potential. Otak dan hati mereka masih jernih belum banyak terkontaminasi oleh pengaruh-pengaruh negatif, sehingga pada usia ini sangat bagus digunakan untuk banyak menghafal Al-Qur'an. The students who graduated from the Salafiyah Ula level are targeted to have memorized 6 juz or on average they are targeted to memorize 1 juz at one year. To achieve that much memorization target, the institution provides a fairly large portion of tahfidz hours, which is 3 hours per day from $07.00-10.30$. The research aims to determine the implementation of tahfidzul Qur'an learning, the results of the implementation of learning tahfidzul Qur'an and to determine the inhibiting and supporting factors for the implementation of class III tahfidzul Qur'an learning at Madrasah Salafiyah Ula Islamic Center Bin Baz Yogyakarta.

This is an open-access article under the CC-BY-SA license. 


\section{Pendahuluan}

Al-Qur'an adalah kalam Allah sebagai pegangan hidup setiap muslim, selain As Sunnah. Al-Qur'an adalah pandu dan lentera bagi manusia dalam menjalani kehidupan ini. Jauh dari Al-Qur'an sama dengan menjadikan hidup ini kering dan hampa tanpa makna.

Al-Qur'an sebagai pedoman hidup memberikan implikasi bahwa, Al-Qur'an selain dibaca harus pula ditadabburi/dihayati maknanya, dan yang paling penting adalah mengamalkan ajaran - ajaran yang terkandung di dalamnya agar kita bisa memperoleh kebahagiaan di dunia dan di akhirat..

Al-Qur'an itu untuk dibaca, dihafal, direnungkan, dan diamalkan. Setiap muslim harus punya semangat dan kecintaan terhadap Al-Qur'an. Rasa cinta akan mendorongnya untuk membaca dan menghafalnya, karena menghafal Al-Qur'an memiliki keutamaan yang sangat besar. Banyak ayat Al-Qur'an dan hadits Nabi shalallahu 'alaihi wasallam yang menunjukkan keutamaan dan kemuliaan para penghafal Al-Qur'an dan pahala yang akan dianugrahkan kepada mereka.

Menghafal Al-Qur'an meskipun terdiri dari 30 juz dan 114 surah, bukanlah hal yang sulit. Allah Subhanahu wa Ta'ala. telah memberikan jaminan mengenai kemudahan dalam mempelajari Al-Qur'an, sebagaimana firman-Nya dalam Surah AlQamar (54) ayat 17 sebagai berikut yang artinya "Dan sesungguhnya telah Kami mudahkan Al-Qur'an untuk pelajaran, maka adakah orang yang mengambil pelajaran ?".

Ayat ini menegaskan bahwa Al-Qur'an itu mudah diingat bagi setiap orang yang menginginkannya, dan kemudahan Al-Qur'an itu juga mencakup dalam hal membacanya, menghafalnya, memahaminya, mentadabburinya, dan menguak keajaibannya. Hakikat ilahiyah yang seharusnya didapatkan terlebih dahulu adalah bahwa Allah akan memudahkan bagi siapa yang bersungguh-sungguh untuk menghafal Al-Qur'an . Kemudian Allah akan mempersiapkan waktu yang tepat baginya untuk menghafal Al-Qur'an, jika dia memang bertekad untuk menghafalnya dan menghadap kepada Allah dengan hatinya yang bersih dan memohon pertolongan kepada-Nya.

Pada zaman sekarang, kita bisa melihat, kebanyakan orang tua lebih resah kalau anaknya tidak bisa matematika atau bahasa Inggris, daripada tidak tahu Al-Quran, padahal mereka adalah keluarga muslim. Sebagai umat Islam kita harus yakin, hanya Al-Quran lah sebagai petunjuk hidup yang bisa membawa keselamatan dunia dan akhirat.

Namun demikian patut kita syukuri , akhir-akhir ini telah banyak muncul kesadaran dari sebagian umat Islam untuk menghafal Al-Qur'an yang ditandai dengan bermunculannya rumah-rumah tahfidz, program/kegiatan tahfidz di kantorkantor maupun sekolah formal, bahkan di beberapa perguruan tinggi. Di samping itu mulai tumbuh pula kesadaran sebagian orangtua untuk mendidik atau menyekolahkan putra putrinya di lembaga-lembaga pendidikan Islam yang mengajarkan hafalan $\mathrm{Al}$ - Qur'an, baik di pondok-pondok pesantren maupun di sekolah-sekolah Islam. Sekarang ini sudah banyak lembaga-lembaga pendidikan Islam yang menjadikan hafalan / tahfidzul Quran sebagai program unggulan.

Islamic Centre Bin Baz ( ICBB ) merupakan salah satu lembaga pendidikan Islam yang mempunyai jenjang pendidikan dari tingkat TK/PAUD, SU/SD, SW/SMP, MA, hingga perguruan tinggi (STITMA). Pada setiap jenjang pendidikan di Islamic Centre Bin Baz mempunyai program / kurikulum tahfidzul Quran.

Pada tingkat Salafiyah Ula (SU) muatan kurikulum tahfidznya paling banyak dibandingkan pada jenjang lainnya. Pengurus ICBB menyadari bahwa anak-anak pada usia SD masih memiliki potensi otak yang luar biasa. Otak dan hati mereka masih jernih belum banyak terkontaminasi oleh pengaruh-pengaruh negatif, sehingga pada usia ini sangat bagus digunakan untuk banyak menghafal Al-Qur'an.

Siswa lulusan jenjang Salafiyah Ula ini ditargetkan mempunyai hafalan 6 juz atau ratarata mereka ditargetkan hafal 1 juz per tahun. Untuk mencapai target hafalan sebanyak itu, maka pihak lembaga memberikan porsi jam tahfidz yang cukup besar yaitu 3 jam per hari 
dari jam $07.00-10.30$.

Atas dasar pemikiran inilah penulis memutuskan untuk mengadakan penelitian guna mengetahui aktifitas kegiatan penghafalan Al-Qur'an yang dilaksanakan pada lembaga tersebut dengan mengambil judul "Pembelajaran Tahfidzul Qur'an di Madrasah Salafiyah Ula Islamic Centre Bin Baz Yogyakarta Tahun Pelajaran 2020/2021.”

\section{Metode}

Penelitian ini digolongkan ke dalam jenis penelitian lapangan (field research) yaitu dalam proses perolehan data sesuai dengan sasaran atau masalah penelitian yang diperlukan sebuah informasi yang selengkap-lengkapnya atau sedalamdalamnya mengenai gejalagejala yang ada dalam lingkup obyek penelitian. Dari gejala-gejala penelitian yang ada dalam penelitian ini bukanlah satu-satunya yang berdiri, melainkan saling berkaitan antara satu sama lain dalam kesatuan yang menyeluruh yang biasanya dikenal dengan pendekatan. dalam penelitian ini, pengumpulan data menggunakan tiga metode utama yaitu : wawancara, observasi dan dokumentasi.

\section{Hasil dan Pembahasan}

\section{Pembelajaran Tahfidzul Qur'an Kelas III Putra Salafiyah Ula ICBB}

a. Tujuan Pembelajaran Tahfidzul Qur'an

Tujuan pembelajaran tahfidzul Qur'an di Madrasah Salafiyah Ula Islamic Centre Bin Baz adalah sebagai berikut:

1) Membentuk siswa yang memiliki aqidah dan akhlak yang qurani.

2) Menanamkan pada siswa sejak dini agar mencintai Al Quran.

3) Siswa mampu membaca dan menghafal Al Quran dengan mutqin (hafalan yang kuat dan tajwid yang benar).

b. Waktu Pembelajaran

Madrasah Salafiyah Ula Islamic Centre Bin Baz menggunakan sistem full day school, dengan pembagian waktu kegiatan belajar setiap harinya sebagai berikut :

1) $07.00-09.00 \quad$ : Tahfidz I

2) $09.00-09.30 \quad:$ Istirahat

3) $09.30-10.20$ : Tahfidz II

4) $10.30-12.00 \quad$ : KBM umum dan diniyah I

5) $12.00-13.00$ : ISHOMA

6) $13.00-14.00$ : KBM umum dan diniyah II

7) $14.00-15.00$ : Ekstra kurikuler

c. Materi Pembelajaran Tahfidzul Qur'an

Materi pembelajaran tahdfizul Qur'an di Madrasah Salafiyah Ula Islamic Centre Bin Baz secara umum ada dua macam, yaitu :

1) Materi tilawah dan tahsin, yang merupakan materi penunjang untuk siswa yang belum bisa membaca Al-Qur'an atau yang bacaan AlQur'annya belum bagus dari sisi tajwid dan makhrojnya.

2) Materi hafalan Al Qur'an, dengan target minimal dari kelas 1 sampai kelas 6 adalah 6 juz yang secara berurutan terdiri dari juz 30 , juz 29, juz 28, juz 27, juz 26, dan juz 1 . Dengan demikian siswa kelas III Salafiyah Ula ICBB minimal harus sudah hafal juz 30, 29, dan 28, atau bagi siswa pindahan minimal dalam 1 tahun hafal 1 juz.

d. Metode Pembelajaran Tahfidzul Qur'an

Menurut Ustadz Damami selaku pengampu sekaligus wali kelas III putra pembelajaran tahfidzul Qur'an di Salafiyah Ula ICBB menggunakan metode sabaq, sabqi, manzil. Dalam 
metode ini hafalan siswa dibagi menjadi 3 macam hafalan yaitu :1

1) Sabaq : Hafalan baru (ayat atau surat yang sedang dihafal)

2) Sabqi : Ayat atau surat yang telah dihafal namun belum genap 1 juz

3) Manzil : Hafalan yang sudah genap 1 juz dan telah diujikan

Setiap hari siswa menyetorkan ketiga macam hafalan tersebut. Hafalan sabaq dan sabqi disetorkan kepada guru tahfidz, sedangkan hafalan manzil disetorkan kepada sesama temannya dengan jumlah setoran sesuai dengan target yang telah ditentukan.

Metode yang digunakan untuk menghafal Sabaq (hafalan baru) adalah dengan menggunakan metode tiqror, yaitu menghafal ayat dengan cara membacanya secara berulang-ulang sebanyak 10-40 kali , baik secara klasikal maupun individual. Secara klasikal guru membacakan ayat yang akan dihafal kemudian diikuti oleh semua siswa dalam satu halaqoh sebanyak 10-40 kali, setelah hafal masing-masing siswa menyetorkan ayat-ayat yang telah dihafal tersebut kepada guru pengampu tahfidz. Adapun secara individual siswa membaca ayat-ayat yang akan dihafal di hadapan guru pengampu sambil dikoreksi tajwid dan makhrojnya, kemudian membaca sendiri ayat-ayat tersebut berulang kali sampai hafal dan disetorkan kepada guru pengampu. e. Media dan Sarana Prasarana

Pembelajaran tahfidzul Qur'an kelas III Salafiyah Ula ICBB menggunakan sarana kelas yang cukup nyaman dengan kipas angin di dalamnya dan santri duduk di kursi lipat yang cukup empuk. Adapun media yang digunakan adalah:

1) Al-Qur'an

2) Buku kontrol hafalan

3) Buku BBQ Karimah

4) $\mathrm{HP} / \mathrm{MP3}$

e. Proses Kegiatan Pembelajaran Tahfidzul Qur'an

Kegiatan pembelajaran tahfidzul Qur'an di kelas III Salafiyah Ula ICBB dibagi dalam tiga waktu yaitu :

1) Pukul 07.00 - 08.00 : untuk menghafal sabaq

2) Pukul $08.00-09.00:$ untuk muroja'ah sabqi

3) Pukul 09.30 - 10.30 : untuk muroja'ah manzil Adapun proses pembelajaran tahfidzul Qur'an di kelas III Salafiyah Ula ICBB adalah sebagai berikut :

1) Pembukaan Pelajaran

Sebelum pembelajaran dimulai guru pengampu mengkondisikan para santri agar duduk dengan tertib dan tenang di kursinya masing-masing, kemudian membuka pembelajaran dengan salam dan ucapan syukur kehadirat Alloh Subhanahu wa Ta'ala. Setelah salam pembuka guru memberikan arahan dan motivasi pada siswa agar rajin dan semangat dalam menghafal Al-Qur'an. Setelah itu guru menyuruh siswa untuk mempersiapkan Al-Qur'annya dan membuka surat dan ayat yang akan dihafal untuk hari tersebut.

2) Penyampaian Materi

Pada satu jam pertama tahfidz (07.00 - 08.00) adalah waktu yang digunakan untuk menghafal hafalan baru (sabaq). Setiap mau menambah hafalan baru para siswa memuroja'ah dulu 1-2 halaman ayat-ayat yang telah dihafal sebelumnya secara bersamasama. Selanjutnya guru membacakan ayat yang akan dihafal dan diikuti oleh kelompok santri yang hafalannya sama sebanyak 10-20 kali. Adapun kelompok siswa yang hafalannya tidak sama mereka disuruh membaca ayat-ayat yang akan dihafal dihadapan guru sambil dikoreksi tajwid dan makhrojnya, kemudian mereka membacanya sendiri sebanyak 10-20 kali / sampai hafal. Kemudian masing-masing siswa menyetorkan ayat-ayat yang telah dihafal kepada guru pengampunya dan menuliskan hasil setorannya tersebut di buku kontrol. Santri yang sudah setor hafalan sabaq disuruh muroja'ah menyiapkan hafalan sabqi yang akan disetorkan pada jam kedua tahfizh. 
Jam kedua tahfizh (08.00-09.00) adalah waktu yang digunakan untuk setoran sabqi. Siswa yang sudah siap, menyetorkan hafalan sabqinya sebanyak 1-2 lembar kepada guru pengampu dan menuliskan hasil setorannya pada buku kontrol tahfizh. Selanjutnya siswa yang sudah selesai setor hafalan sabqi memuroja'ah menyiapkan hafalan manzilnya yang akan disetorkan pada jam ketiga tahfizh.

Jam ketiga tahfizh (09.30-10.30) adalah waktu yang digunakan untuk muroja'ah hafalan manzil. Metodenya dengan saling setor sesama siswa atau dengan memuroja'ah bersamasama dipimpin guru pengampu. Banyaknya hafalan manzil yang dimuroja'ah antara 1/4 - $1 / 2$ juz per hari.

3) Penutup pelajaran

Sebelum menutup kegiatan pembelajaran tahfizh guru pengampu memberikan motivasi kepada para siswa agar senantiasa belajar dengan baik, kemudian memberikan tugas hafalan atau tugas muroja'ah di rumah dengan menuliskannya pada buku kontrol tahfizh dan penghubung orangtua siswa. ${ }^{2}$

f. Evaluasi dan Penilaian Pembelajaran Tahfidzul Qur'an

Ada tiga macam evaluasi yang dilakukan dalam pembelajaran tahfidzul Qur'an di Salafiyah Ula Islamic Centre Bin Baz, yaitu : ${ }^{8}$

1) Evaluasi Harian

Siswa selalu dipantau dan dievaluasi setiap hari oleh guru pengampu tahfizh dan hasilnya dicatat dalam buku kontrol tahfizh.

Tabel 1 : Lembar Setoran pada Buku Kontrol Tahfizh 1 SETORAN HAFALAN SABAQ DAN SABQI

\begin{tabular}{|c|c|c|c|c|c|c|c|c|}
\hline \multirow{9}{*}{ Hari/Tgl } & \multirow{3}{*}{$\begin{array}{c}\text { Setoran } \\
\text { Sabaq }\end{array}$} & \multirow{3}{*}{$\begin{array}{l}\text { Jumlah } \\
\text { Setoran }\end{array}$} & \multirow{2}{*}{\multicolumn{2}{|c|}{$\begin{array}{c}\text { Jumlah } \\
\text { Kesalahan }\end{array}$}} & \multirow{3}{*}{$\begin{array}{c}\text { Setora } \\
\text { n } \\
\text { Sabqi }\end{array}$} & \multirow{3}{*}{$\begin{array}{l}\text { Jumlah } \\
\text { Setoran }\end{array}$} & \multirow{2}{*}{\multicolumn{2}{|c|}{$\begin{array}{c}\text { Jumlah } \\
\text { Kesalahan }\end{array}$}} \\
\hline & & & & & & & & \\
\hline & & & $\mathrm{H}$ & $\mathrm{T}$ & & & $\mathrm{H}$ & $\mathrm{T}$ \\
\hline & & .....brs & & & & .......lbr & & \\
\hline & & ......brs & & & & ......lbr & & \\
\hline & & .....brs & & & & ......lbr & & \\
\hline & & ......brs & & & & ......lbr & & \\
\hline & & .....brs & & & & ......lbr & & \\
\hline & & .....brs & & & & ......lbr & & \\
\hline \multicolumn{9}{|c|}{ Penambahan hafalan selama 1 pekan $=\ldots$...baris $/$.....halaman } \\
\hline & falan & ai pekan i & & & & & & \\
\hline
\end{tabular}

$$
\text { Keterangan : } \mathrm{H}=\text { Hafalan, } \mathrm{T}=\text { Tajwid }
$$

Syarat lulus / diterima setoran adalah apabila setoran sabaq tidak ada kesalahan, sedangkan untuk setoran sabqi, hafalan maksimal salah 2 dan tajwid salah 4 .

Tabel 2 : Lembar Setoran Pada Buku Kontrol Tahfizh 2

SETORAN MANZIL DAN TILAWAH Bulan.............Pekan
ke......

\begin{tabular}{|c|c|c|c|c|c|c|c|}
\hline Hari/Tgl & $\begin{array}{c}\text { Setoran } \\
\text { Manzil }\end{array}$ & $\begin{array}{c}\text { Jumlah } \\
\text { Setoran }\end{array}$ & $\begin{array}{c}\text { Jumlah } \\
\text { Kesalahan }\end{array}$ & $\begin{array}{c}\text { Setoran } \\
\text { Tilawah }\end{array}$ & Nilai & $\begin{array}{c}\text { Tugas } \\
\text { Hafalan }\end{array}$ & $\begin{array}{c}\text { Tanda } \\
\text { Tangan }\end{array}$ \\
\hline
\end{tabular}




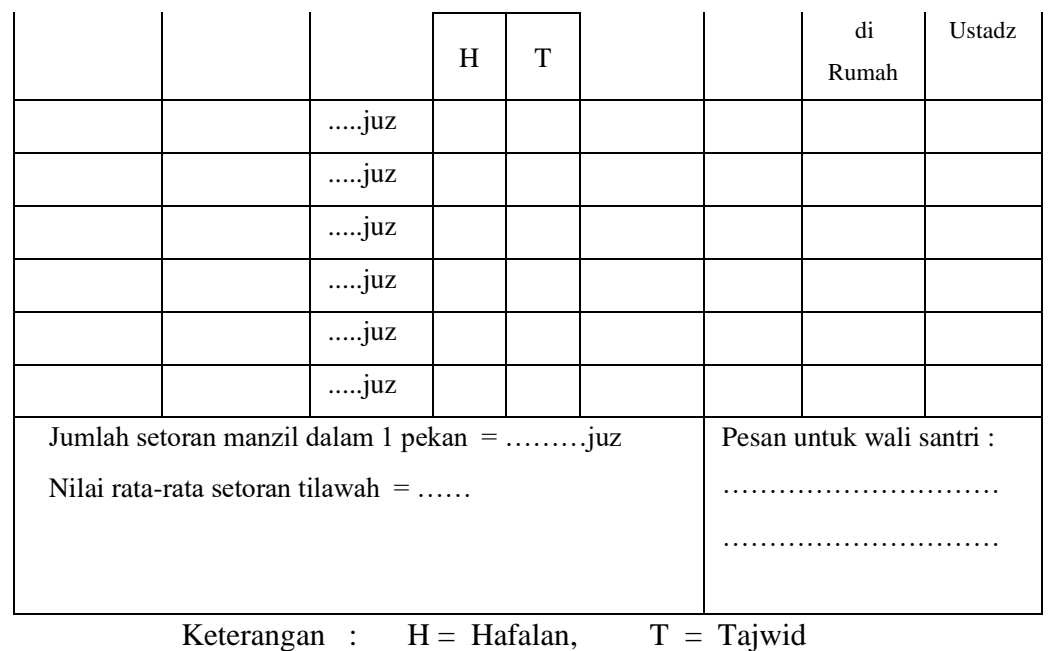

Syarat lulus / diterima setoran manzil adalah apabila kesalahan hafalan setoran manzil maksimal salah 4 dan tajwid maksimal salah 8. Adapun untuk penilaian setoran tilawah, apabila tidak ada kesalahan maka nilai maksimal 100 dan apabila ada kesalahan maka 1 kesalahan mengurangi 10 point dari point 100.

2) Penilaian Ujian Kenaikan Juz

Ujian kenaikan juz adalah ujian yang dilakukan terhadap siswa setiap menyelesaikan hafalan 1 juz. Apabila lulus siswa tersebut boleh melanjutkan hafalan ke juz berikutnya. Namun apabila tidak lulus maka dia harus mengulang ujian sampai lulus.

Metode penilaiannya adalah siswa menyetorkan 1 juz hafalan yang diujikan kepada guru penguji sekali duduk dari awal sampai akhir. Guru penguji kemudian menghitung jumlah kesalahan hafalan dan tajwidnya. Dalam 1 juz jumlah kesalahan tidak boleh lebih dari 10 atau nilai minimalnya adalah $100-10=90$.

3) Penilaian Ujian Akhir Semester

Setiap akhir semester siswa diuji seluruh hafalannya dengan metode dan sistem penilaian yang sama seperti ujian kenaikan juz. Dalam sehari siswa diuji 1 juz. Hafalan siswa dikatakan mutqin (kuat) apabila nilai rata-rata ujian lebih dari 90, hafalan baik apabila nilai rataratanya 81 - 90, hafalan sedang apabila nilai rata-ratanya 70 - 80 dan dikatakan kurang apabila nilai rata-ratanya di bawah 70 . Nilai hasil ujian akhir semester dijadikan sebagai nilai raport tahfidz khusus di luar raport KBM ( pelajaran umum dan diniyah).

\section{Hasil Pembelajaran Tahfidzul Qur'an Kelas III Putra Salafiyah Ula ICBB}

Hasil pembelajaran tahfidzul Qur'an kelas III putra Salafiyah Ula Islamic Centre Bin Baz ini diambil dari data raport tahfizh semester genap tahun pelajaran 2020/2021, yaitu sebagai berikut :

\begin{tabular}{|c|c|c|c|c|c|c|c|}
\hline No & Nama Santri & Lama & Jumlah & Pencapaian & Nilai Rata-rata Ujian per Juz & Rat & Kualitas \\
\hline
\end{tabular}




\begin{tabular}{|c|c|c|c|c|c|c|c|c|c|c|c|}
\hline & & Belajar & Hafala $\mathrm{n}$ & Target & $\begin{array}{r}\text { Juz } \\
30\end{array}$ & $\begin{array}{r}\text { Juz } \\
29\end{array}$ & $\begin{array}{r}J u z \\
28\end{array}$ & $\begin{array}{r}\text { Juz } \\
27\end{array}$ & $\begin{array}{r}\text { Juz } \\
26\end{array}$ & $\begin{array}{c}\mathrm{a} \\
\text { rata }\end{array}$ & Hafalan \\
\hline 1 & Abdul Hafizh & 3 tahun & 3 & Tercapai & 94 & 93 & 88 & & & 91.5 & Mutqin \\
\hline 2 & A.Sa`dan & 3 tahun & 2 & Tidak & 80 & 79 & & & & 82.0 & Baik \\
\hline 3 & A. Yusuf & 3 tahun & 2 & Tidak & 92 & 95 & & & & 93 & Mutqin \\
\hline 4 & Ahmad Thoif & 3 tahun & 5 & Tercapai & 92 & 88 & 79 & 89 & 92 & 88.1 & Baik \\
\hline 5 & Anasif Almas & 3 tahun & 3 & Tercapai & 88 & 86 & 87 & & & 87.0 & Baik \\
\hline 6 & Dhiya A & 3 tahun & 5 & Tercapai & 92 & 85 & 92 & 91 & 80 & 88.0 & Baik \\
\hline 7 & Fauzan & 3 tahun & 1 & Tidak & 82 & & & & & 82.0 & Baik \\
\hline 8 & $\begin{array}{l}\text { Fuad Al } \\
\text { Ikhsan }\end{array}$ & 1 tahun & 1 & Tercapai & 97 & & & & & 97.0 & Mutqin \\
\hline 9 & $\begin{array}{c}\text { Ghaza Islam } \\
\mathrm{H}\end{array}$ & 1 tahun & 2 & Tercapai & 91 & 76 & & & & 83.5 & Baik \\
\hline 10 & Handan. F & 3 tahun & 3 & Tercapai & 97 & 96 & 82 & & & 91.7 & Mutqin \\
\hline 11 & Haris Mashad & 1 tahun & 2 & Tercapai & 84 & 79 & & & & 81.5 & Baik \\
\hline 12 & $\begin{array}{c}\text { Ilham Faqih } \\
\text { M }\end{array}$ & 3 tahun & 5 & Tercapai & 82 & 85 & 85 & 87 & 80 & 83.9 & Baik \\
\hline 13 & Khobab A & 3 tahun & 5 & Tercapai & 80 & 78 & 82 & 97 & 93 & 86.1 & Baik \\
\hline 14 & Muh. Asto & 3 tahun & 3 & Tercapai & 89 & 91 & 85 & & & 88.5 & baik \\
\hline 15 & M.Athif. S & 3 tahun & 3 & Tercapai & 89 & 83 & 0 & & & 57,5 & Buruk \\
\hline 16 & Muh. Hibban & 3 tahun & 5 & Tercapai & 84 & 83 & 84 & 93 & 90 & 86.8 & Baik \\
\hline 17 & Salman & 3 tahun & 2 & Tidak & 79 & 77 & & & & 78.3 & Sedang \\
\hline 18 & Umar & 3 tahun & 5 & Tercapai & 94 & 85 & 0 & 50 & 94 & 64,6 & Buruk \\
\hline 19 & Zaki Zabarijas & 1 tahun & 2 & Tercapai & 85 & 88 & & & & 86.5 & Baik \\
\hline 20 & $\begin{array}{l}\text { Zuhdan } \\
\text { Raufan }\end{array}$ & 3 tahun & 5 & Tercapai & 81 & 96 & 82 & 50 & 84 & 78.4 & Sedang \\
\hline \multicolumn{10}{|c|}{ Rata-Rata Kelas } & 83,9 & Baik \\
\hline
\end{tabular}

Catatan :

$\mathrm{H}=$ nilai Hafalan, $\mathrm{T}=$ nilai Tajwid

Nilai 0 : siswa tidak ikut ujian pada juz tersebut

Dari data di atas diketahui bahwa ada 4 siswa yang tidak terpenuhi target jumlah hafalannya, yaitu Abdulloh Sa'dan, Abdurrahman Yusuf, Fauzan, dan Salman. Rata-rata kualitas hafalan siswa kelas Salafiyah Ula ICBB sudah cukup bagus kecuali Salman dan Zuhdan yang kualitas hafalannya sedang serta M. Athif Shalahuddin dan Umar yang mempunyai hafalan buruk karena tidak ikut ujian pada juz 28.

\section{Faktor-Faktor Pendukung dan Penghambat dalam Pembelajaran Tahfidzul Qur'an Kelas III Putra Salafiyah Ula Islamic Centre Bin Baz}

a. Faktor-Faktor Pendukung Pembelajaran Tahfidzul Qur'an 
Berdasarkan hasil wawancara dengan guru pengampu tahfidz dan wali kelas 3 putra Salafiyah Ula ICBB diketahui bahwa faktor pendukung pembelajaran tahfidzul Qur'an kelas III putra di Salafiyah Ula Islamic Centre Bin Baz tahun pelajaran 2015/2016 adalah sebagai berikut : ${ }^{3}$

1) Faktor Tenaga Pendidik

(a) Guru-guru pengajar tahfidz adalah para guru yang telah terbina dengan baik aqidah dan akhlaknya.

(b) Para guru pengajar tahfidz mempunyai latar belakang pendidikan tahfizh dan sebagian dari mereka sudah hafidz Al Qur'an, termasuk yang mengajar di kelas III putra Salafiyah Ula ICBB.

(c) Para guru mempunyai motivasi dan semangat yang yang tinggi dalam mengajarkan Al-Qur'an kepada murid-muridnya.

(d) Para guru mampu memotivasi dan mengkondisikan siswa ketika belajar.

(e) Para guru mampu menjalin komunikasi dan kerjasama dengan orangtua / wali dalam mendidik para siswa baik melalui media buku kontrol, HP, maupun bertemu secara langsung.

2) Faktor Siswa

(a) Siswa yang memiliki kemampuan dan kecerdasan yang baik dalam menghafal AlQur'an

(b) Siswa yang memiliki motivasi dan semangat yang tinggi dalam menghafal Al-Qur'an

(c) Sikap disiplin siswa di setiap pembelajaran tahfidz

(d) Faktor Orang tua dan Keluarga Siswa

(e) Orang tua / wali siswa yang memiliki kesadaran tinggi akan pentingnya menghafal AlQur'an bagi putra/putrinya.

(f) Sikap dan kerjasama orang tua / wali siswa dalam mendukung kegiatan muroja'ah dan belajar menghafal Al-Qur'an di rumah.

(g) Kondisi keluarga siswa yang harmonis

3) Faktor Sarana Prasarana dan Sistem Pembelajaran

(a) Lingkungan sekolah yang tenang dan kondusif untuk belajar karena berada di tengah sawah jauh dari pemukiman penduduk.

(b) Kondisi kelas yang cukup nyaman untuk belajar.

(c) Tersedianya mushaf Al-Qur'an yang cukup dan diberikan secara gratis kepada para siswa.

(d) Tersedianya buku kontrol tahfidz dan penghubung orang tua siswa, yang berfungsi untuk mengontrol hafalan dan mengetahui perkembangan hasil pembelajaran tahfidz siswa sekaligus sebagai media penghubung dengan orang tua.

(e) Pemberian hadiah berupa voucher belanja gratis di kantin bagi yang telah lulus ujian kenaikan juz dan bagi santri yang mempunyai hafalan terbanyak di kelasnya.

(f) Diadakan Musabaqoh Hifdzul Qur'an (MHQ) setiap tahun sekali dan siswa diikutkan pada MHQ yang diadakan di luar sekolah.

(g) Faktor Penghambat Pembelajaran Tahfidzul Qur'an

4) Faktor peserta didik

(a) Sebagian siswa memiliki daya ingat yang lemah.

(b) Sebagian siswa kurang motivasi dan semangatnya dalam menghafal Al-Qur'an.

(c) Sebagian siswa ada yang cenderung sangat aktif sehingga kurang konsentrasinya ketika menghafal.

(d) Siswa tidak memuroja'ah kembali hafalannya di rumah, sehingga hafalannya kurang kuat.

5) Faktor Guru

(a) Sebagian guru khidmah (santri lulusan madrasah aliyah ICBB yang mengabdi 1 tahun 
di pondok) belum mampu untuk mengelola halaqoh tahfizh dengan baik.

(b) Sebagian guru khidmah kurang disiplin dalam mengajar.

6) Orangtua

(a) Kurangnya perhatian orangtua terhadap putranya dalam memberikan motivasi dan semangat untuk mempersiapkan hafalan sabaq dan memuroja'ah hafalan manzil di rumah.

(b) Terlalu sibuknya / kurang mampunya orangtua untuk menyimak tugas muroja'ah siswa di rumah.

(c) Kondisi hubungan anggota keluarga siswa yang kurang harmonis.

\section{Simpulan}

\section{Proses Pembelajaran Tahfidzul Qur'an}

a. Salah satu tujuan pembelajaran tahfidz di Salafiyah Ula Islamic Centre Bin Baz adalah menjadikan siswa bisa hafal Al-Qur'an secara mutqin (kuat) dengan target hafalan 1 juz per tahun atau siswa lulus kelas 6 mampu hafal 6 juz, yaitu juz $30-26$ dan juz 1. Untuk memenuhi target tersebut maka alokasi waktu yang disediakan untuk pembelajaran tahfidz di Salafiyah Ula Islamic Centre Bin Baz cukup besar, yaitu 3 jam per hari dari jam $07.00-10.30$ yang diselingi istirahat 30 menit.

b. Metode yang digunakan dalam pembelajaran tahfidzul Qur'an di Salafiyah Ula ICBBadalah metode sabaq, sabqi, manzil. Metode yang menggabungkan antara program menghafal baru (sabaq) dan muroja'ah (sabqi, manzil) secara komprehensif, sehingga santri memiliki hafalan yang mutqin (kuat). Metode menghafal baru menggunakan metode tikror, yaitu dengan cara membaca ayat yang akan dihafal secara berulang-ulang sampai hafal.

c. Media yang digunakan dalam pembelajaran adalah Al Qur'an, buku kontrol, buku BBQ Karimah, dan HP/MP3/MP4

\section{Hasil Pembelajaran Tahfidzul Qur'an}

a. Secara kuantitas hafalan, dari data raport tahfidz kelas III putra Salafiyah Ula Islamic Centre Bin Baz diketahui bahwa hasil pembelanjaran tahfidzul Qur'an kelas III putra Salafiyah Ula ICBB sudah cukup berhasil . Hal ini dibuktikan dari 20 santri yang ada hanya 4 santri $(20 \%)$ yang tidak terpenuhi target penambahan hafalan 1 juz per tahun atau target jumlah hafalan 3 juz.

b. Hasil pembelajaran tahfidzul Qur'an kelas III putra Salafiyah Ula ICBB secara kalitas hafalan sudah cukup bagus. Hal ini dibuktikan dari hasil ujian keseluruhan hafalan nilai rata-ratanya adalah 83,9 .

\section{Faktor Pendukung dan Penghambat Pembelajaran Tahfidzul Qur'an}

a. Faktor-faktor yang mendukung pembelajaran tahfidz kelas III putra Salafiyah Ula ICBB adalah tenaga pendidik yang memiliki kemampuan dan dedikasi yang tinggi dalam tahfidz, kemampuan dan semangat santri dalam menghafal, motivasi dan dukungan kerjasama orangtua, serta sarana prasarana yang cukup memadai dan nyaman.

b. Faktor-faktor yang menghambat pembelajaran tahfidz kelas III Salafiyah Ula ICBB adalah lemahnya daya ingat dan berkurangnya konsentrasi siswa pada saat pembelajaran berlangsung, kurang mampunya sebagian guru khidmah (pengabdian) untuk menguasai dan mengatur halaqoh, kurangnya motivasi dan dukungan dari orangtua ketika di rumah, dan latar belakang keluarga santri yang kurang harmonis. 


\section{Saran-saran}

a. Kepada guru pengampu tahfidz kelas III putra:

1) Selalu meluruskan niat dengan mengikhlaskan diri dalam mengajarkan Al-Qur'an kepada para siswa.

2) Selalu berupaya untuk memotivasi siswa agar mempunyai semangat yang tinggi dalam menghafal Al-Qur'an.

3) Berupaya untuk selalu disiplin pada saat pembelajaran tahfidz.

4) Senantiasa menjalin hubungan dan kerjasama yang baik dengan orangtua dalam pengajaran tahfidz maupun dalam menangani permasalahan-permasalahan siswa. b. Kepada peserta didik:

(a) Selalu meluruskan niat untuk ikhlas dalam menghafal Al-Qur'an.

(b) Diharapkan semua siswa mengikuti kegiatan tahfidzul Qur'an dengan semangat dan kesungguhan.

(c) Selalu memuroja'ah hafalan dan menyiapkan hafalan berikutnya di rumah dengan cara mendengarkan murottal Al-Qur'an melalui CD , MP3, atau media yang lainnya.

b. Kepada orangtua/wali siswa kelas III putra :

1) Diharapkan orangtua selalu mengikuti perkembangan pencapaian tahfidz anak dengan melihat buku kontrol dan membantu putranya dalam melaksanakan tugas rumah yang diberikan.

2) Diharapkan orangtua selalu berkomunikasi dan bekerjasama dengan guru pengampu dalam menghadapi permasalahan pembelajaran tahfidz putranya.

\section{Daftar Pustaka}

Depag RI, Al-Qur'an dan terjemahnya, Semarang: Raja Publishing, 2011

Departemen Agama RI. Al-Qur'an dan Terjemahnya. Jakarta : Darus Sunnah, 2007

https://khazanahilmublog.wordpress.com/informasi/pesantren/pondok-pesantren-islamiccentrebin-baz-yogyakarta/

Dudung Abdurrohman, Pengantar Metodologi Penelitia, (Yogyakarta: Kurnia Kalam Semesta, 2003)

Husna Nashihin, Kontektualisasi Strategi Pembelajaran Nabi, (Semarang: CV. Pilar Nusantara, 2019)

Juklak Pembelajaran Tahfizhul Qur'an Salafiyah Ula ICBB, 2020/2021

Juklak Pembelajaran Tahfizhul Qur'an Salafiyah Ula, 2020/2021 